\title{
Observation of a Positive and Constructive Teacher-Child Interaction in Pre-School Setting in Selangor Malaysia
}

\author{
Nordin Mamat ${ }^{1}$, Siti Rahayu Isha ${ }^{2}$, Abdul Rahim Razalli ${ }^{3}$, Mazlina Che Mustapha ${ }^{4}$ \& Rosmarzila Omar ${ }^{5}$ \\ ${ }^{12345}$ Faculty of Human Development, Sultan Idris Education University, MALAYSIA \\ E-mail: nordin@fpm.upsi.edu.my
}

\begin{abstract}
The primary aim of this study is to investigate positive and constructive teacher-child interaction. The study involved 65 children from 4 pre-schools and their teachers. A qualitative methodology was applied in this study. Observations of the children were conducted over 12 weeks, in classroom activities, and were recorded in field notes and with a digital camera to gain understanding of the interaction based on instruments. The children were interviewed based on observations and photographs conducted earlier. In-depth interviews were conducted with the teachers according to the child observation and interview data. The result shown interaction between teachers and children come with polite language and the practice of - budi bahasa" as a symbol of respectfulness. Teacher facilitated children with appropriate language and good manner. Teacher character such caring, soft spoken (intonation), body language become model for children in interaction to their peer and influence child's character. In conclusion, the study gives a picture of the importance of contextual factors such as teachers influencing child 's interaction. The implications of these results for research in teachers-child, for future research should emphasis on how the level and quality of teacher-child remains.
\end{abstract}

Keywords: Early childhood, child's interaction, teacher characteristic

\section{Introduction}

Teachers and children need to interact and be tolerant and respectful in learning activities. Interaction encompasses praise, persuasion, instruction, prompting, advice and included non-verbal interaction such as touching and facial expression. These interactions used by pre-school teachers in learning activities are channels for establishing a harmonious relationship between them. Teachers who use smiles appropriately can encourage children and promote positive interaction. Meanwhile children who can feel a teacher's concern and respect for them will have a sense of being valued, accepted, and feel that they are taken care of and loved (Loy, Aminah \& Nordin, 2015; Neill, 2017; Mehrabian, 2017). The aim of this study is to investigate 
positive interaction in classroom activities and how the learning activities promote positive interaction between teacher -child and among children.

\section{Literature Review}

Interaction in learning activities is a key process for a teacher to deliver skills and knowledge to children (Nordin, et al 2018; Nordin et al 2019). Through interaction, a teacher can implement activity planning based on the learning outcomes. According to Warneken, Chen \& Tomasello (2006), positive interaction demonstrates some form of shared intentionality. Interaction based on react to one another's actions, and they have intentions toward the other's intentions; they must understand the intentions of the other and incorporate them into their own intention. Therefore, interactions play an important role in learning activities to engage in learning processes and enhance children's experience, skills and knowledge (Siti Noor Fauzah and Nik Suryani, 2013, Norsita and Zainal, 2014, Nordin et al 2019). For a better interaction results, teachers can create suspense appropriately for children's attention and concentration. Teachers and children establish a positive relationship of mutual trust and respect through verbal interaction. Teachers should express their concern and love through various forms encompasses a smile, sympathetic words and appropriate touch gestures encompasses hugs and pats to make the child feel loved and cared for. Teachers should pay attention to the standardization of speech and speak. The voice should be clear and smooth. Voice and intonation are important components of verbal interaction. When used properly, children can feel the beauty of language and interaction can happen effectively (Hruska, 2017; Remsperger-Kehm, 2017; Nordin et al 2019). Teachers also can use body language that encompasses gestures, eye contact and facial expressions to the transmission of information through hand and finger activities. The teacher's gestures not only have the function of emphasizing and demonstrating, but also more clearly expresses encouragement than just words. Eye contact is a particularly important non-verbal communication skill. The eyes reflect and express emotions (O'Kane \& Goldbart, 2016; Mehrabian, 2017). Corsaro (2006) believed that positive interaction is reproduction of culture which views children's peer culture as a stable set of activities or routines, values, and concerns that children produce and share in interaction with peers as an interpretive reproduction of adult culture.

\section{Methodology}

This study uses qualitative data. A total of four (4) teacher and four (4) assistant teacher in Selangor Malaysia and 65 pre-school children were selected in this study. They were observed and interviewed based on observation checklist related teacher-child interactions during learning activities. This research instrument is partly derived from the research Development of a Comprehensive and Integrated Model of Quality Malaysian Early Childhood Care and EducationProject 3/TLA: Determining Contributing Factors of Quality ECCE. The instrument was divided into two sections. Section A included verbal interaction and Section B included non-verbal interaction between teacher and children.

\section{Findings}

\subsection{Facilitated Appropriate Language and Polite Body Language}

Every morning, the children met their teacher at the gate and they gave greetings such as salam, selamat pagi (good morning) to the teacher and assistant teacher.

\section{At 7.45 am: Children started arriving at the pre-school. The teacher normally arrived at the pre-school at 7.30 am. After keeping the stuff in the pre-school office, at 7.40 am Cikgu Faziah would stand at the gate and keep the gate open. [...] This started with a Chinese girl with her mum arriving at the pre-school gate, the parent said good morning to the teacher and gave a greeting in Mandarin to the assistant teacher. A child (Canny) conveyed the greeting also to the teacher and researcher. She held the teacher's right hand and then kissed it. After that she went to classroom accompanied by the assistant teacher. As usual, she left her shoes on the shelves beside the door. (General Observation: Morning Routine Episode)}

Children who are always polite to the teacher and give greetings to others. The children showed respect to the teacher and assistant teacher. According to the assistant teacher's statement:

She (May Yin) really respects her teacher. She loves her teacher. Her mum bought a cake for her birthday; she wanted her teacher to have some. (Interview assistant teacher)

The appropriate behaviour in children. Some children would like to show respect to others by doing things which they observe are cultural practices of their family. For example, some children would greet his/her friends using a 'noticeable phrase' known only to his/her friends' culture. Based on observation, teacher started with greeting every morning and followed with "dua". Teacher asked politely to their children using soft intonation at least three times reminders. For example, first teacher looks at children and gives salam. Follow by children, address somebody using "saalam" even non-muslim because they would be excited 
with Malays. To them, "assalamualaikum (a frequent address among Muslims, meaning "May peace always be upon you") or "Wa'laikum saalam" (May peace be upon you too) is the same as (in Malay), "Selamat sejahtera" (Be in good condition always) and then they understand the meaning of all that. The best practice of this study is shown how greeting develop children with good characteristics through preschool routines like "dua" and kissing hands. After that teacher touch children's shoulder and their head, that behavior was happen in spontaneous action to make sure children followed the rules.

\subsection{Shared Play Activities Trigger Positive Interaction}

It seems important in this study to investigate how activity promote interaction such as the play activity that the children were involved in. Most of the observation showed that the children relate to each other because of the shared play activities. The type of play is different according to the children; it is subject to the group or situation but the play emphasise here is the type of play initiated by the children. For example, here we have a type of play activity that a group of children created:

Marleen saw Husem and Vikejay jumping on the green carpet with a square shape design on the floor. They played with the carpet shape. She went to Husem and Vikejay to play with them. She imitated what they did which was jumping inside the shapes. (Observation Session 1: Child 12)

In this case, a group of children created a type of play Teng Teng, jumping on the floor based on a carpet shape. The children carried out their assigned roles among their group and imagined that the square shape design on the floor was part of their rules. Children created and engaged in cooperative play. Cooperative play occurs when two or more children are engaged in a play activity. This play activity initiated an interaction, communication and understanding with other children who were involved. They were copying the activity that the others were doing and showing their willingness to become friends. The children communicated through the activity they were involved in together and had the same feelings towards each other.

The case below could be described as similar to the one above:

Suri followed Waki, she put a pencil between her nose and her mouth and showed it to Asma. They looked happy with this play activity. (Observation P065: Child 15)
Like the case before, a friend is a play partner, so the children relate to each other because they need a partner to interact or to share the fun with. Another case explains how play activities trigger the children to build relationships. They forgot about their ethnic group and gender when they were involved in playing enjoyable games. The following case is from my observation and interview:

Marlen [Chinese girl] and Vikejay observed what Husem was doing. Husem told them the rules of the game and what to do.

When I asked about what was their relationship to him, Husem told me that they were all his friends. He always played with them during free time and when they were doing outdoor activity. He said that Zizii always gave coloured pencils to him when he needed them.

When I asked Zi Ni about her relationship with Harun, she said that they always played together during play time. She was also Harun's friend in classroom activities.

When I asked them together, Husem, Zizii, Marlen and Vikejay admitted they were friends. (Observation P071: Child 7)

Referring to this case, children understood friendship as playing together and sharing together. In this case the triggers of relationships here included feeling comfortable with another child when they were playing. Through play they developed relationships and became closer. When they admitted that they liked to be friends with most of those who interacted in the above case, this gave a picture about the play activities, and how they developed relationships without taking into account gender and ethnic groups. By playing together, they were building up their bond of friendship.

\subsection{Teacher Encouraged Interaction by Seating Arrangement for Developing Sociability}

Teacher encouraged interaction by seating arrangement of their students. We found that the teacher and assistant teacher were busy rearranging the children's seating early in the morning. They changed and shifted a few children between the groups. We realised that the teacher rearranged children every week to make sure children close to each other. The teacher explained below

\section{$R$ : Why is there a need for this seating formation?}

Teacher: This is one of the factors to get children close to each other...em...mm of course at the early stage they [children] look uncomfortable and difficult to make friends...but after a few days it was alright. 
Teacher: Actually, this idea is one of the suggestions from the education district department to the teachers who have been teaching less than 5 years. Physically it has been effective [lah] so far. It seems they show cooperative behaviour, helpful, respecting each other. At least we can see them playing and chatting with other group members. (Paragraphs 84-98)

By doing this, the teachers construct Zones of Proximal Development (ZPD) for the children and lay out a step-by-step learning route which is tailored to the needs and abilities of the children. It is evident that the teacher has a significant influence on what happens in the classroom. The nature of that influence depends on the constraints of the situation, on the teacher's personal beliefs, expectations and attitude, and on how the teacher interprets the behaviour of children. As a result there is an increasing variation in the ways teacher interact with the children in her classroom.

In these pre-school, the children's seating arrangement had been set up by the teacher and assistant. According to the assistant teacher, maybe this arrangement would make it easier for the teacher to conduct class discussions or small group activities, as suggested by the following statement from the assistant teacher,

$$
\begin{aligned}
& \text { Eer ... We put them in small groups... } 5 \text { to... } 6 \text { people for } \\
& \text { the teacher to arrange group activities ... easy for the } \\
& \text { teacher to watch ... they cooperate with each other ... no } \\
& \text { matter what ethnic group or race... (Paragraph } 36 \text { ) }
\end{aligned}
$$

According to the explanations above, the children were also developing sociability among themselves. The above explanation suggests that children of different background in pre-school "mixed" together as a result of the mixed seating arrangement in the classroom. According to the assistant teacher, the major aim for the classroom sitting arrangement is to encourage children to communicate and to enhance the children's language development. This seating formation helps them to build positive interactions. From the observations, this cluster seating arrangement seems useful for group discussion, cooperative learning, or small group tasks. In this arrangement, the children were asked to move their chairs and face the teacher. To sum up, the classroom sitting arrangement is believed to be a crucial method to promote the children's social interaction development.

\section{Discussion}

In terms of interactions, all teachers give praise, advice and use persuasion, instruction and prompting to children during learning activities. Teacher-Child verbal interaction uses polite words to express themselves. In terms of non-verbal interactions, all teachers employ sign language during learning activities such as facial expressions, the tone and pitch of the voice, gestures and use touching on children during learning activities. Various patterns of children's behaviour have emerged from this study: granting or conveying polite greetings to the teachers, kissing the hands of teachers; follow the rules and regulations of pre-school; follow norms such as waiting in a queue and lining up to wait in a queue; and standing at the right distance to indicate respect. Based on typical scenes of teacher - child interaction, teacher-planned seating has led to peer interaction. The children show a willingness to help, share and cooperate with other children This behaviour would positively prompt children to interact regularly with others. These behaviours were also related to the group seating pattern formed by the teacher in order to encourage children's sharing. That the ability to cooperate with others develops further in the pre-school years is consistent with the findings of Warneken, Chen \& Tomasello (2006), positive interaction demonstrates some form of shared intentionality. In this case, children do not just react to one another's actions, but they have intentions toward the other's intentions; they must understand the intentions of the other and incorporate them into their own intention. Most of the pre-school activities provide an environment for sharing and stimulate cooperative behaviour in the children.

The importance of positive interaction from children towards others. This behaviour is significantly emphasised in pre-school. Based on my observation, pre-school children from different groups have to respect friends, teachers, assistant teachers. They show respectful behaviour either through greeting and hand kissing, or by using good body language. We discovered that there were several cases of children who were perhaps practices polite language and respectful during interaction among with teachers and peer. Being respectful with polite language and positive body language is very prominent in the Malaysian cultures. These findings are in line with Corsaro (2006) who views children's peer culture as a stable set of activities or routines, values, and concerns that children produce and share in interaction with peers as an interpretive reproduction of adult culture (Corsaro, 2006). These are transformed constructively within activities in the local cultures that make up their everyday lives such as family, pre-school, and peer group.

\section{Conclussion}

The study's findings show that, teacher-child interaction uses polite words to express themselves and employ sign language during learning activities such as facial expressions, the tone and pitch of the voice, gestures and use touching on children. These various patterns of behaviour have emerged from this study such as granting or conveying polite 
greetings to the teachers, kissing the hands of teachers; follow the rules and regulations of pre-school; follow norms such as waiting in a queue and lining up to wait in a queue. In conclusion, the study gives a picture of the importance of contextual factors such as teachers influencing child's interaction. The implications of these results for research in teachers-child, for future research should emphasis on how the level and quality of teacher-child remains.

\section{Acknowledgemet}

This part of the research "Development of a comprehensive and integrated model of quality Malaysian early childhood care and education-project 3/TLAA: determining contributing factors of quality ecce" (2015-0024-106-04-3) is funded by the Ministry of Finance through the Malaysian Ministry of Education. Special appreciation is also dedicated to the National Child Development Research Centre, Universiti Pendidikan Sultan Idris, Malaysia for giving us the opportunity to carry out this research project.

\section{References}

[1] Corsaro, W. A. (2006). Qualitative research on children's peer relations in cultural context. In X. Chen, D. C. French \& B. H. Schneider (Eds.), Peer Relationships in Cultural Context (1 ed., pp. 96-122). Cambridge: Cambridge University Press.

[2] Hruska, C.A. (2017). Strategies for teacher learning and development over child-adult interactions in ECE settings. In Gunn, A.C \& Hruska, C.A. (Ed). Interactions in early childhood education: Recent research and emergent concepts. Singapore: Springer.

[3] Loy, C. L., Aminah, A. \& Nordin, M. (2015). Aktiviti boneka jari membentuk interaksi sosial kanak-kanak. Jurnal Pendidikan Awal Kanak-Kanak Kebangsaan. Volume 4., Number 1. 2015. 29-49.

[4] Mehrabian, A. (2017). Nonverbal communication. New York: Routledge.

[5] Neill, S. (2017). Classroom nonverbal communication. England: Routledge Revivals.

[6] Norsita A. \& Zainal M. (2014). Tinjauan awal interaksi guru-kanak-kanak dalam pemupukan pemikiran kreatif kanak-kanak prasekolah. In Proceeding of the Social Sciences Research. (Pp. 735-746). Sabah: Worldconferences.Net.

[7] Nordin Mamat, Loy Chee Luen, Nor Mashitah Mohd Radzi, Sopia Md Yassin \& Syahida Iryani Mohd Yusoff (2018) Reliability, Validity and Fairness of Interviews for Teaching and Learning Project in Quality Early Childhood Care and Education: Preliminary Study. International Journal of Academic Research in Business and Social Sciences Vol. 8 , No. 6 2018. 1283-1292.
[8] Nordin Mamat, Loy Chee Luen, Nor Mashitah M. Radzi, Mazlina Che Mustapha, Abdul Rahim Razalli \& Abdul Talib M. Hashim (2019) Children's Experience and Learning Opportunities in PERPADUAN (Unity) PreSchool Settings. International Journal of Academic Research in Business and Social Sciences Vol.98 , No. 5 2019. Pg 971-980.

[9] O'kane, J.C. \& Goldbart, J. (2016). Communication before speech: Development and assessment. London: David Fulton Publishers.

[10] Remsperger-Kehm. (2017). Sensitive Responsiveness: An approach to the analysis and improvement of teacherchild interaction in early childhood settings. In Gunn, A.C \& Hruska, C.A. (Ed). Interactions in early childhood education: Recent research and emergent concepts. Singapore: Springer.

[11] Siti Noor Fauziah A. R. \& Nik Suryani N. A. R. (2013). Children interaction patterns exhibited during learning activities: A case study at a selected public kindergarten in Malaysia. In Prosiding International Conference on Social Science Research. (Pp.1389-1412). Penang: Worldconferences.Net.

[12] Warneken, F., Chen, F., \& Tomasello, M. (2006). Cooperative Activities in Young Children and Chimpanzees. Child Development, 77(3), 640-663. 